\title{
A Modified Normalization Method for Determining Fracture Toughness of Steel
}

\author{
Hui Gao ${ }^{1}$, Weigang Wang ${ }^{2}$, Yanlin Wang ${ }^{1}$, Bohua Zhang ${ }^{2}$, and Chun-Qing Li ${ }^{2}$ \\ ${ }^{1}$ RMIT University \\ ${ }^{2}$ Affiliation not available
}

June 14,2020

\begin{abstract}
Normalization method is a practical method for determining the J-R curves and fracture toughness of steels. There is some concern, however, about the performance of this method on steels with small strain hardening exponent and yield strength due mainly to the assumption of infinite strain hardening exponent (n). This paper intends to analytically modify the normalization method by removing this assumption and incorporating the strain hardening in calculating the blunting corrected crack length. This modification enables the normalization method to be applied to steels with small strain hardening exponent and yield strength. Experiments are undertaken to prove the underperformance of the normalization method for steels with small strain hardening exponent and yield strength and to verify the modified normalization method (CNM). A comparison of fracture toughness determined by CNM with that by the unloading compliance method and normalization method corroborates the improved accuracy of the developed CNM. It is found in the paper that the developed CNM performs very well for materials with small strain hardening exponent and yield strength and performs better for specimens with smaller thickness and in accordance with all standards. The paper concludes that the developed CNM overcomes the deficiency of the normalization method for steels with small strain hardening exponent and yield strength.
\end{abstract}

\section{Hosted file}

GH02_modified normalization method_submit to FFEMS_140620.pdf available at https://authorea. com/users/333335/articles/459556-a-modified-normalization-method-for-determiningfracture-toughness-of-steel 